06

Рост микрокристаллов алмаза

по механизму ориентированного

присоединения при высоком давлении

\title{
и температуре
}

(C) С.В. Кидалов, Ф.М. Шахов, А.В. Швидченко, А.Н. Смирнов, В.В. Соколов, М.А. Яговкина, А.Я. Вуль

Физико-технический институт им. А.Ф. Иоффе РАН, Санкт-Петербург

E-mail: Kidalov@mail.ioffe.ru

Поступило в Редакцию 15 июля 2016 г.

Впервые экспериментально показано, что при использовании в качестве реакционной смеси порошка детонационных наноалмазов (ДНА) вместе с предельным ациклическим углеводородом, одноосновным или многоосновным спиртом, последующая обработка при высоких давлениях 5-8 GPa и температурах $1300-1800^{\circ} \mathrm{C}$ приводит к образованию монокристаллов алмазов с размерами до $15 \mu \mathrm{m}$. Спектр комбинационного рассеяния света свидетельствует о совершенстве кристаллической решетки алмаза. Предполагается, что формирование монокристаллов алмаза микронных размеров из частиц ДНА размером около $5 \mathrm{~nm}$ при указанных технологических условиях происходит по механизму ориентированного присоединения.

DOI: 10.21883/PJTF.2017.01.44085.16417

Структурный фазовый переход графит-алмаз уже несколько десятилетий является предметом детальных исследований. Причина этого вполне понятна - этот фазовый переход лежит в основе промышленного синтеза алмаза из графита при высоких давлениях и температурах, так называемого НРНТ-синтеза. Обычно НРНТ-синтез алмаза происходит в присутствии металла катализатора [1]. Типичные значения давлений и температур составляют $P=5-8 \mathrm{GPa}, T=1200-2000^{\circ} \mathrm{C}$, исходным материалом является смесь графита и металла катализатора, время синтеза варьируется от десятков секунд до десятков минут и даже нескольких дней для получения крупных монокристаллов [2]. При этих условиях синтез происходит в термодинамически равновесных условиях в $P-T$-области стабильности алмаза в отличие от осаждения из газо- 
вой фазы, так называемый CVD-синтез, при котором синтез происходит вне $P-T$-области стабильности алмаза. Получаемые НРНТ-методом алмазные микропорошки имеют размеры от десятков до сотен микрон и содержат примеси металла катализатора, что ограничивает возможные области их применений.

Нанотехнологии, и в первую очередь технология создания биомаркеров [3], определили необходимость получения алмазных кристаллов с размерами в нанометровой области. Механическое измельчение и последующее фракционирование НРНТ-алмазов позволило получить алмазные частицы с размерами до $10 \mathrm{~nm}$, но при сложном многоступенчатом процессе [4]. Альтернативный способ получения алмазных кристаллов нанометровых размеров - детонационный синтез из углерода взрывчатых веществ - позволил получить алмазные водные суспензии и порошки с размерами кристаллов $4-5 \mathrm{~nm}$ [5]. Исследование фазовых переходов при повышенных температурах и давлениях таких детонационных наноалмазов (ДНА) выявило ряд необычных особенностей. Так, при длительном отжиге порошка ДНА при температурах $600-800^{\circ} \mathrm{C}$ в атмосфере водорода был обнаружен фазовый переход атомов углерода в тонком поверхностном слое из $s p^{2}$ - в $s p^{3}$-гибридизованное состояние, что соответствует переходу от графитовой к алмазной структуре [6]. Такой тип перехода отличается от традиционных представлений о неизбежной трансформации алмаза в графит при нагревании при атмосферном давлении. В [6] также сообщалось, что в процессе отжига ДНА в водороде наблюдалось образование кристаллов с размерами до $0.1 \mathrm{~mm}$, что позволило выдвинуть предположение о связи этого эффекта с непосредственной компактацией частиц ДНА в объемные монокристаллы.

Указание на возможность формирования из порошка ДНА частиц микронных размеров при высокотемпературном спекании можно найти в работах [7-9], при этом в [9] была высказана идея о механизме роста алмаза из наночастиц ДНА как за счет коалесценции наночастиц, так и за счет присоединения к ним отдельных атомов углерода или небольших углеродных кластеров, присутствующих в исходном материале в виде примесей.

В недавно опубликованной статье [10] сообщалось об изучении процесса рекристаллизации ДНА в присутствии водородсодержащих флюидов при давлении 6-8 GPa и температуре выше $1300^{\circ} \mathrm{C}$ и показано, что в присутствии водородсодержащего флюида происходит формирование микронных алмазных кристаллов. Авторы предположили, что в

Письма в ЖТФ, 2017, том 43, вып. 1 
области термодинамической стабильности алмаза увеличение размеров кристаллов происходит за счет укрупнения частиц ДНА, которые выступают в роли центров кристаллизации. При этом источником атомов углерода служат водородсодержащие флюиды, разлагающиеся при высокой температуре.

В работах [11] рассматривается широко изучаемый в последнее время рост кристаллов по методу ориентированного присоединения. Однако возможность роста алмазов по такому механизму не была известна. В данной работе излагаются результаты исследования влияния различных органических соединений и спиртов на спекание порошка ДНА в $P-T$-области стабильности алмаза. При постановке эксперимента исходили из того, что рост алмазных частиц происходит по механизму ориентированного присоединения. Именно такой механизм был предложен нами ранее для объяснения существенного увеличения области когерентного рассеяния (ОКР) алмазных кристаллов, обнаруженного при спекании порошков ДНА при высоких давлениях и температурах $[12,13]$.

В отличие от роста алмаза из графита в присутствии металла катализатора, который в расплавленном виде является ростовой средой, в представленной статье речь идет об эксперименте, в котором такая „ростовая среда“ отсутствует. В процессе спекания не происходит фазовых превращений графита в алмаз или алмаза в графит, так как графитизации наноалмаза не происходит. При выбранных $P-T$-параметрах процесс происходит в области стабильности алмаза. Это было показано ранее авторами в работе [14].

Успешный синтез микрокристаллических алмазов с размерами от $500-1000 \mathrm{~nm}$ и до нескольких микрон при спекании ДНА при давлениях 5-8 GPa и температурах $1300-1800^{\circ} \mathrm{C}$ при добавлении к порошку ациклических углеводородов и/или одноосновных спиртов подтвердил правильность предложенного механизма [15].

Для НРНТ-спекания в настоящей работе использовался порошок ДНА высокой степени очистки, полученный по технологии, описанной в работе [16]. Количество несгораемых примесей составляло не более $0.1 \mathrm{wt} \%$. Размер ОКР в порошке до спекания составлял $4-5 \mathrm{~nm}$, распределение частиц по размерам в гидрозоле из такого же порошка соответствовало этому значению.

К порошку ДНА до спекания добавлялся один из предельных ациклических углеводородов, в том числе гексан и парафин. Было

Письма в ЖТФ, 2017, том 43, вып. 1 

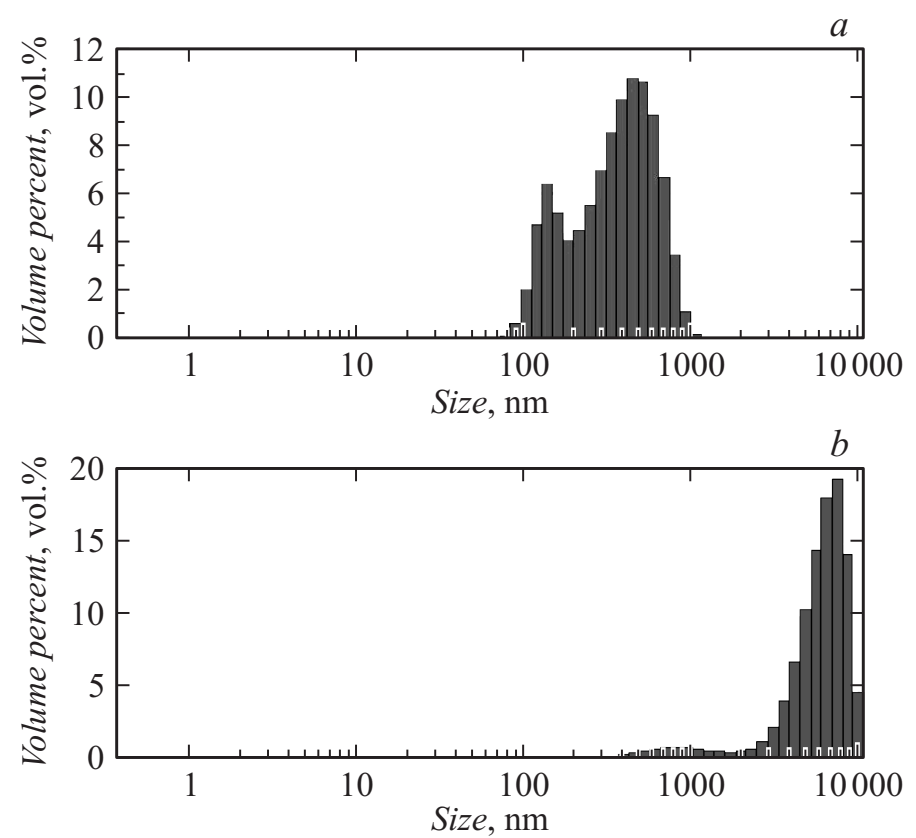

Рис. 1. Объемное распределение частиц по размеру: $a-$ для верхней (неоседающей) части гидрозоля, $b$ - для оседающей части гидрозоля.

изучено также влияние одно- и/или многоосновных спиртов, в том числе этилового или изопропилового спирта, этиленгликоля, глицерина, пентаэритрита и ксилита. Во всех случаях добавка углеводородов производилась в концентрации от 5 до $60 \mathrm{wt} \%$.

Спекание порошка ДНА проводилось в камерах высокого давления типа „тороид“. Выдержку полученного состава проводили при статическом давлении 5-8 GPa и температуре $1300-1800^{\circ} \mathrm{C}$ в течение 10-90 s. Детали использованной аппаратуры описаны в предыдущих работах $[12,13,17,18]$.

После спекания образцы очищались от материала контейнеpa $\left(\mathrm{CaCO}_{3}\right)$ в кислотах $\mathrm{HBr}$ и/или $\mathrm{HCl}$ и от неалмазного углерода (остатков графитового нагревателя) методом гравитационного разделения в бромоформе $\left(\mathrm{CHBr}_{3}\right.$ - жидкость с плотностью $\left.2.9 \mathrm{~g} / \mathrm{cm}^{3}\right)$. После

Письма в ЖТФ, 2017, том 43, вып. 1 


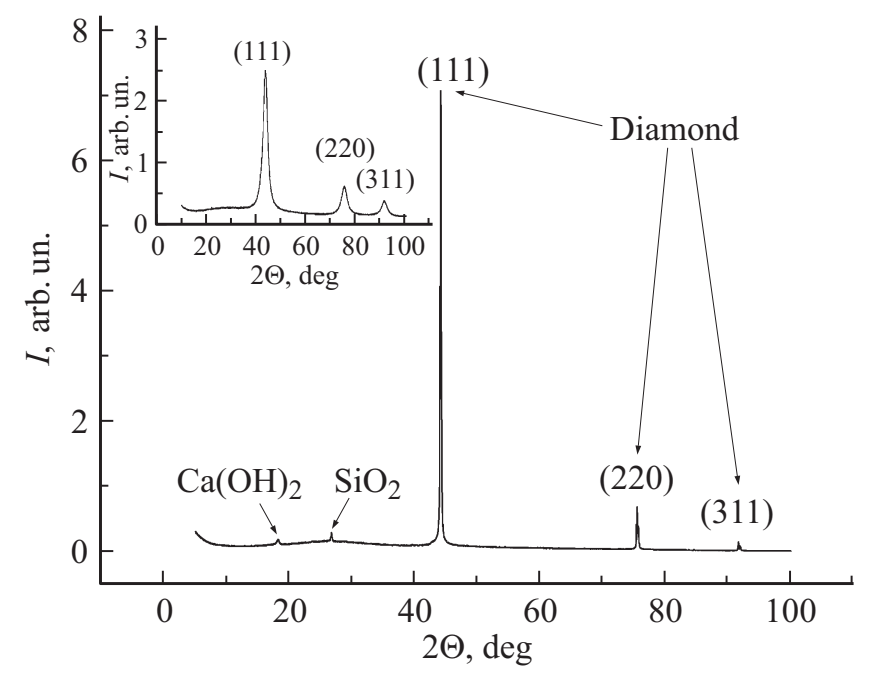

Рис. 2. Рентгенофазовый анализ синтезированных микрокристаллов алмазов. Видны остатки диоксида кремния и кальция в виде $\mathrm{Ca}(\mathrm{OH})_{2}$, содержащихся в контейнере высокого давления. На вставке показана дифрактограмма исходного ДНА.

указанной очистки, промывки в деионизованной воде и высушивания образцы представляли собой белый порошок.

Массовый выход получаемых порошков микрокристаллов составляет от 90 до $100 \mathrm{wt} \%$ от массы порошка ДНА, загруженного в контейнер высокого давления. Этот факт говорит о росте микрокристаллов алмаза из исходного порошка ДНА без участия значительного количества других компонентов.

Структура полученных образцов была исследована методами рентгеновской дифракции, сканирующей электронной микроскопии, спектроскопии комбинационного рассеяния света.

Размер частиц измерялся в гидрозоле методом динамического рассеяния света. При измерении распределения полученных алмазных частиц в гидрозоле со временем наблюдалось оседание более крупных частиц. На рис. 1, $a$ представлено объемное распределение частиц для верхней (неоседающей) части гидрозоля, а на рис. $1, b$ - для нижней части гидрозоля. Видно, что при спекании удается получать частицы с

Письма в ЖТФ, 2017, том 43, вып. 1 

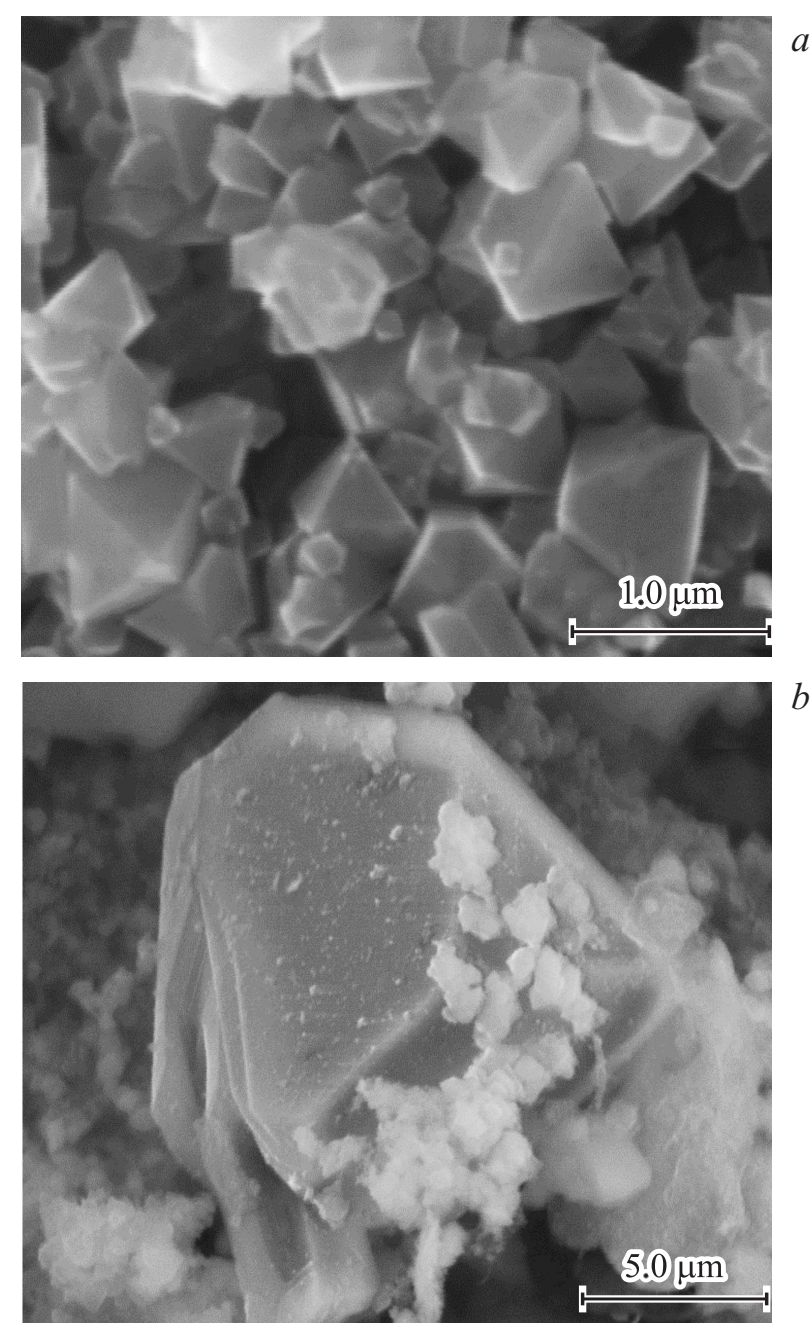

Рис. 3. СЭМ-изображения синтезированных алмазов $(a, b)$. Масштабная линейка: $a-1 \mu \mathrm{m}, b-5 \mu \mathrm{m} . b-$ большой кристалл алмаза размером около $15 \mu \mathrm{m}$. $c$ - спектр КР света синтезированного кристалла алмаза, полученный при возбуждении $\mathrm{Ar}^{+}$-лазером $\left(\lambda_{e x}=476 \mathrm{~nm}\right)$ (символы). Пунктирная линия аппроксимация контура фононной линии $\left(1332.3 \mathrm{~cm}^{-1}\right)$ функцией Лоренца; ширина этой линии на половине высоты составляет $2.9 \mathrm{~cm}^{-1}$.

Письма в ЖТФ, 2017, том 43, вып. 1 


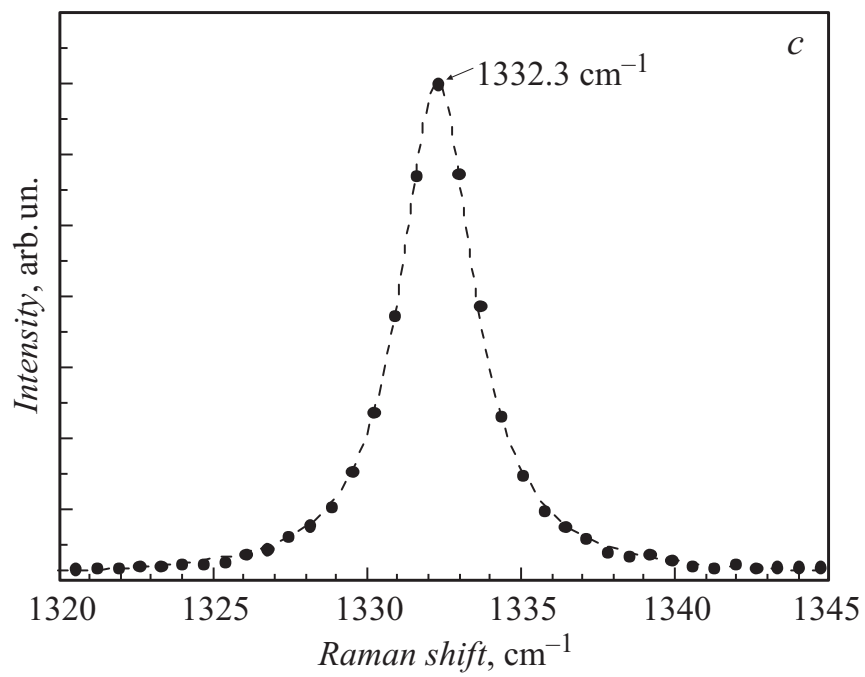

Рис. 3 (продолжение).

размерами от $70 \mathrm{~nm}$ до $15 \mu \mathrm{m}$, при этом в объеме золя преобладают частицы размером более $4 \mu \mathrm{m}$.

Рентгеновский дифракционный анализ (дифрактометр D2 Phaser, $\left.\mathrm{Cu} K_{\alpha}\right)$ подтвердил образование алмазных кристаллов с размерами, существенно превышающими размер ОКР исходного ДНА (рис. 2), и выявил присутствие двух фаз $-\mathrm{SiO}_{2}$ и $\mathrm{Ca}(\mathrm{OH})_{2}$ в количестве не более $2 \mathrm{wt} \%$. Источник $\mathrm{SiO}_{2}$, по всей видимости, связан с материалом используемого контейнера, в который помещался порошок ДНА для спекания. Это было подтверждено при исследовании элементного состава полученных алмазных микрокристаллов (СЭМ Quanta 200), которое показало, что основными примесями являются кальций и кислород, входящий в состав контейнера высокого давления. В отдельных кристаллах алмаза был обнаружен также $\mathrm{Si}$ в количествах, не превышающих $0.15 \mathrm{wt} \%$, источником которого также может служить материал контейнера.

Как видно из рис. 3, $a, b$, кристаллы синтезированного алмаза представляют собой ограненные монокристаллы с размерами до $15 \mu \mathrm{m}$. Большая часть кристаллов имеет форму октаэдров. Спектр комбинаци-

Письма в ЖТФ, 2017, том 43, вып. 1 
онного рассеяния (КР) света получен при возбуждении $\mathrm{Ar}^{+}$-лазером $\left(\lambda_{e x}=476 \mathrm{~nm}\right)$. Полуширина полосы алмаза $\left(1332.3 \mathrm{~cm}^{-1}\right)$ составляет $2.9 \mathrm{~cm}^{-1}$ (рис. $3, c$ ). Этот параметр соответствует высококачественным синтетическим алмазам, получаемым НРНТ-синтезом из графита с металлами-катализаторами (как правило, менее $3 \mathrm{~cm}^{-1}$ [19]) и указывает на достаточно высокое совершенство кристаллической решетки синтезированных алмазов.

Таким образом, экспериментально показано, что при использовании в качестве реакционной смеси порошка детонационных наноалмазов вместе с предельным ациклическим углеводородом, одноосновным или многоосновным спиртом последующая обработка при высоких давлениях $5-8 \mathrm{GPa}$ и температурах $1300-1800^{\circ} \mathrm{C}$ приводит к образованию монокристаллов алмазов с размерами до $15 \mu \mathrm{m}$. Спектр комбинационного рассеяния света свидетельствует о совершенстве кристаллической решетки алмаза. Предполагается, что формирование монокристаллов алмаза микронных размеров из частиц ДНА размером около $5 \mathrm{~nm}$ при указанных технологических условиях происходит по механизму ориентированного присоединения.

Авторы благодарят Алексенского А.Е. за подготовку ДНА для НРНТ-спекания, Возняковского А.А. за помощь в химической очистке полученных микрокристаллов.

Исследования были поддержаны РНФ (проект № 14-13-00795). Ф.М. Шахов благодарит за поддержку программу Президента Российской Федерации для государственной поддержки молодых российских ученых — кандидатов наук (проект МК-6048.2015.3). Рентгеновская дифрактограмма была получена на оборудовании ЦКП „Материаловедение и диагностика в передовых технологиях“.

\section{Список литературы}

[1] Верещагин Л.Ф. // Синтетические алмазы и гидроэкструкция. М., 1982.

[2] Ulrika F.S. D'Haenens-Johansson et al. // Gems \& Gemology, Fall. 2015. V. 51. N 3.

[3] Zhang X. et al. // J. Colloid Interface Sci. 2013. V. 397. P. 39-44.

[4] Boudou J.-P. et al. // Diamond Relat. Mater. 2013. V. 37. P. 80-86.

[5] Mochalin V.N. et al. // Nat. Nanotechnol. 2012. V. 7. P. 11-23; Vul' A., Shenderova $O$. (eds.) // Detonation Nanodiamonds. Science and Applications. Pan Stanford Publishing, 2014. 
[6] Алексенский А.Е. и др. // ФТТ. 2000. Т. 42. В. 8. С. 1531-1534.

[7] Витязь П.А., Сенють В.Т. // ФТТ. 2004. Т. 46. В. 4. С. 743-745; Сенють В.T., Мосунов Е.И. // ФТТ. 2004. Т. 46. В. 4. С. 746-748.

[8] Даниленко В.В. // ФТТ. 2004. Т. 46. В. 4. C. 693-697; Yushin G.N. et al. // Diamond Relat. Mater. 2005. V. 14. N 10. P. 1721-1729.

[9] Давыдов В.А. и др. // Письма в ЖЭТФ. 2007. Т. 86. В. 7. С. 530-533.

[10] Варфоломеева Т.Д. и др. // Неорганические материалы. 2016. Т. 52. В. 4. C. $396-401$.

[11] Qiao Zhang et al. // J. Mater. Chem. 2009. V. 19. P. 191-207.; Rui-Qi Song, Helmut Colfen // Adv. Mater. 2010. V. 22. P. 1301-1330; Weiqiang Lv. et al. // Nanoscale. 2014. V. 6. P. 2531-2547.

[12] Kidalov S.V. et al. // Diamond Relat. Mater. 2010. V. 19. N 7-9. P. 976-980.

[13] Kidalov S.V. et al. // Crystallography Report. 2011. V. 56. N 7. P. 97-101.

[14] Kidalov S.V. et al. // Diamond Relat. Mater. 2008. V. 17. P. 844-847.

[15] Патент РФ № 2576055. Шахов Ф.М. и др. Способ получения кристаллических алмазных частиц. 2013.

[16] Aleksenskiy A.E., Eydelman E.D., Vul' A.Ya. // Nanosci. Nanotechnol. Lett. 2011. V. 3. P. $68-74$.

[17] Davidenko V.M. et al. // Diamond Relat. Mater. 2004. V. 13. N 11-13. P. $2203-$ 2206.

[18] Kidalov S.V. et al. // Phys. Sol. State. 2008. V. 50. N 5. P. 981-985.

[19] Zaitsev A.M. // Opt. Propert. Diamond. Berlin, Heidelberg: Springer-Verlag, 2001.

Письма в ЖТФ, 2017, том 43, вып. 1 